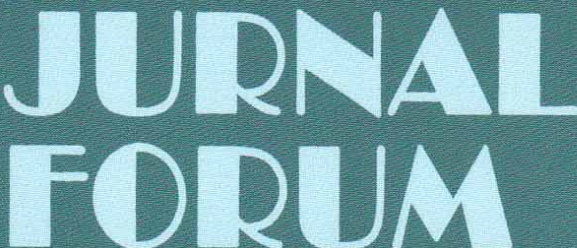

Volume 7 - Nomor 1

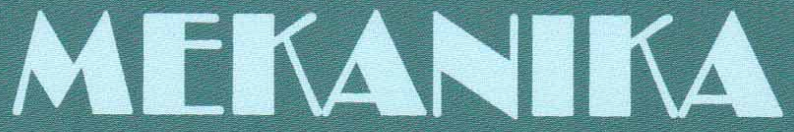

Mei 2018

ISSN : 2356-1491

PENGARUH FLY ASH DENGAN PENAMBAHAN CACAHAN KARET, SILICA FUME DAN SUPERPLASTICIZER TERHADAP BETON

TRI YUHANAH; TOMMY IDUWIN; BUDI WICAKSONO

PERILAKU STRUKTUR TOWER TRANSMISI TIPE SUSPENSION TERHADAP BEBAN ANGIN MUHAMMAD SOFYAN; DICKI DIAN PURNAMA; ABDUL ROKHMAN

IDENTIFIKASI PENYEBAB KECELAKAAN KERJA PADA PROYEK KONSTRUKSI BANGUNAN GEDUNG TINGGI

RETNA KRISTIANA; SLAMET

STUDI SIFAT MEKANIS TANAH MERAH DENGAN PENGUJIAN TRIAKSIAL REFFANDA KURNIAWAN RUSTAM

ANALISIS PENGARUH BESAR BUTIRAN AGREGAT KASAR TERHADAP KUAT TEKAN BETON NORMAL IKA SULIANTI; AMIRUDDIN; RIO SHAPUTRA; DARYOKO

ANALISIS BANJIR DAN TINGGI MUKA AIR PADA RUAS SUNGAI CILIWUNG STA 7+646 S/D STA $15+049$

IKA SARI DAMAYANTHI SEBAYANG; MELIANA PARLINA

ANALISIS KELAYAKAN PERENCANAAN PEMBANGUNAN JALAN PENGHUBUNG (MISSING LINK) ANTARA DESA SIKUR SAMPAI DESA PAOKMOTONG KABUPATEN LOMBOK TIMUR

DESSY ANGGA AFRIANTI; SIGIT IRFANSYAH; MEYRISSA PUTRI DEWANDARI 


\title{
ANALISIS PENGARUH BESAR BUTIRAN AGREGAT KASAR TERHADAP KUAT TEKAN BETON NORMAL
}

\author{
IKA SULIANTI \\ Jurusan Teknik Sipil, Politeknik Negeri Sriwijaya \\ E-mail : ikasulianti74@gmail.com \\ AMIRUDDIN \\ Jurusan Teknik Sipil, Politeknik Negeri Sriwijaya \\ E-mail : nafamart@gmail.com \\ RIO SHAPUTRA \\ Jurusan Teknik Sipil, Politeknik Negeri Sriwijaya \\ E-mail : rioshaputra@gmail.com \\ DARYOKO \\ Jurusan Teknik Sipil, Politeknik Negeri Sriwijaya \\ E-mail : daryoko11@gmail.com
}

\begin{abstract}
Abstrak
Penelitian ini bertujuan untuk mengetahui apakah pengaruh besar butir agregat kasar berpengaruh terhadap nilai kuat tekan yang ditargetkan, terhadap mutu kuat tekan beton. Penelitian ini bersifat penelitian kuantitatif yang dimulai dari pengujian material-material yang digunakan sebagai bahan penyusun beton dan pembuatan mix design Tata Cara Pembuatan Rancangan Beton Normal berdasarkan SNI 03-2834-2000. Analisa data yang digunakan menggunakan metode statistic dengan membandingkan nilai rata-rata kuat tekan dari berbagai bentuk sampel. Dari hasil analisa didapatkan adanya pengaruh kuat tekan beton yang besar butiran agregat kasar berbeda-beda. Besar butir agregat kasar juga berpengaruh terhadap nilai kuat tekan dengan kecenderungan semakin besar butir agregat kasar yang digunakan maka kuat tekan yang dihasilkan akan semakin besar.
\end{abstract}

Kata kunci : Besar butir agregat kasar, sampel beton kubus, kuat tekan beton

\begin{abstract}
The purpose of this research is to know whether the influence of bulk aggregate grains influence the targeted compressive strength value, test sample to concrete compressive strength. This research is a quantitative research that starts from the testing of materials used as concrete materials and make the concrete mix design based on the procedure to make normal concrete on SNI 03-2834-2000. The analyzing data using simple statistical method by comparing the average value of compressive strength from various sample forms. From the result of analysis, obtained data from of compressive strength achieved with the bulk of the granular aggregate grains used differently. The coarse aggregate grain also affects the compressive strength value with the greater tendency of coarse aggregate grains used, the greater the compressive strength.
\end{abstract}

Key Word : size of graved aggregates, cuboid concrete sample, concrete compressive strength

\section{Latar Belakang}

Konstruksi adalah satu kata yang sangat familiar, mengingat pembangunan yang terus berkembang pesat saat ini. Konstruksi yang baik dapat dilihat dari tahapan pelaksanaan yang berkualitas. Seiring berkiembangnya teknologi konstruksi bangunan maka makin sering pula digunakannya beton sebagai struktur konstruksi. Dalam pelaksanaannya beton banyak digunakan sebagai bahan dalam pembuatan kolom, balok dan plat lantai serta bendungan hingga material penyusun dalam pelaksanaan pekerjaan kosntruksi jalan, karena beton memiliki banyak fungsi inilah maka dalam proses pelaksaan pembuatannya perlu diperhatikan berbagai macam hal, mulai dari perencanaan campuran beton itu sendiri hingga proses pelaksanaan dan perawatannya.

Untuk lebih mengenal karakteristik beton, diperlukan pemahaman tentang beton itu sendiri. Hal ini berguna agar dalam pengerjaannya beton dapat digunakan sesuai dengan ketentuan dan keefektifan dari awal proses hingga selesai 
pengerjaan. Selain tahap pelaksanaan yang sesuai, konstruksi beton yang baik juga didukung oleh material-material yang digunakan untuk menyusun konstruksi tersebut menjadi lebih berkualitas adalah penggunaan material beton sehemat mungkin dengan kekuatan yang didapat cukup tinggi.

Namun seiring dengan pelaksanaannya, hasil kekuatan pengujian beton di lapangan sering kali tidak sesuai dengan sampel beton yang diambil sebagai benda uji ukuran butir agregat kasar yang akan digunakan juga akan mempengaruhi kuat tekan beton tersebut. Maka dari itu dilakukan penelitian berjudul "Analisis Pengaruh Besar Butiran Agregat Kasar pada Sampel Beton Inti Terhadap Kuat Tekan Beton Normal”.

\section{Landasan Teori}

\section{Beton}

Beton merupakan sebuah elemen penting yang dapat dipakai hampir di setiap pekerjaan konstruksi dimasa sekarang ini. Beton sendiri merupakan sebuah satuan yang terdiri dari perhitungan komposisi agregat halus, agregat kasar, semen sebagai bahan pengikat, dan air sebagai bahan utama yang mengaktifkan sifat mengikat pada semen.

\section{Sejarah Perkembangan Beton}

Hingga bangunan yang paling banyak diminati adalah beton. Hal ini disebabkan karena lain oleh kemudahan untuk dibuat menjadi berbagai bentuk dan dari segi ekonomi bahan beton adalah paling murah bila dibandingkan konstruksi baja atau kayu, lebih tahan terhadap bahaya kebakaran, serta relatif kaku.

Di samping itu beton mempunyai beberapa kekurangan seperti kekuatan fisik tarik yang rendah, memerlukan bekisting dan penumpu saat konstruksi, perbandingan kekuatan terhadap berat yang relatif lebih rendah dan stabilitas volumenya relatif rendah.

Pemakaian beton telah dimulai sejak zaman Romawi. Namun baru pada awal abad 19 bahan beton mengalami banyak perkembangan.

1. Tahun 1801, F. Coignet menemukan bahan beton mempunyai kekuatan tarik yang rendah.

2. Tahun 1824, Aspidin penemu Portland semen.

3. Tahun 1850, J.L. Lambot berhasil membuat perahu kecil dari bahan semen.

4. Tahun 1867, J. Monier, petani Perancis, mempatenkan rangka baja sebagai tulangan untuk gentong beton yang ia buat.

5. Tahun 1888, Kolnen untuk pertama kali memperkenalkan teori dan perencanaan struktur beton.

6. Tahun 1906, C.A.P. Turner memperkenalkan pelat rata tanpa balok.

7. Tahun 1938, teori kekuatan batas (ultimate strength design) di USSR.
8. Tahun 1956, teori kekuatan batas di USA dan Inggris.

Perkembangan lebih lanjut dari teknologi beton adalah diperkenalkannya beton mutu tinggi dengan kuat tekan dapat mencapai 13,5 Mpa dan kuat tarik sebesar 12,5 Mpa. Selain itu dikenal pula jenis-jenis beton lainnya seperti beton berserat (fiber concrete), beton ringan (light weight concrete), beton polimer (polymer concrete), latex modified concrete, gap-graded concrete, no-fines concrete dan lain-lain.

\section{Material Penyusun Beton}

Berikut ini adalah material-material yang merupakan komposisi campuran beton:

\section{Semen Portland (PC)}

Semen Portland adalah semen hidrolis yang dihasilkan dengan cara menghaluskan klinker yang terutama dari silikat-silikat kalsium yang bersifat hidrolis dengan gips sebagai bahan tambahan. Semen Portland merupakan bahan ikat penting dan banyak dipakai dalam pembangunan fisik. Fungsi dari semen adalah mengikat butir-butir agregat hingga membentuk suatu massa padat dan mengisi rongga-rongga udara di antara butir-butir agregat. Walaupun sebagai bahan pengikat makan peranan semen sangat penting. Semen yang digunakan untuk pekerjaan beton harus disesuaikan dengan rencana kekuatan dan spesifikasi teknik yang diberikan. Senyawa-senyawa kimia dari semen Portland adalah tidak stabil secara termodinamis, sehingga sangat cenderung untuk bereaksi dengan air. Untuk membentuk produksi hidrasi dan kecepatan bereaksi dengan air dari setiap komponen adalah berbedabeda, maka sifat-sifat hidrasi masing-masing komponen perlu dipelajari.

1. Tricalsium Silikat $\left(\mathrm{C}_{3} \mathrm{~S}\right)=3 \mathrm{CaO} . \mathrm{SiO}_{2}$

2. Dicalsium Silikat $\left(\mathrm{C}_{2} \mathrm{~S}\right)=2 \mathrm{Cao} \mathrm{SiO}_{2}$

3. Tricalsium Alumnat $\left(\mathrm{C}_{3} \mathrm{~A}\right)=3 \mathrm{Cao} \cdot \mathrm{Al}_{2} \mathrm{O}_{3}$

4. Tetracalsium Aluminoferit $\left(\mathrm{C}_{4} \mathrm{AF}\right)=$ 4CaO. $\mathrm{Al}_{2} \mathrm{O}_{3} \mathrm{FeO}_{3}$

Dua unsur pertama yakni Tricalsium Silikat dan Dicalsium Silikat peda semen merupakan penyusun utama dalam pembuatan semen sehingga merupakan bagian paling dominan dalam memberikan sifat semen. Bila semen terkena air, $\mathrm{C}_{3} \mathrm{~S}$ segera mulai berhidrasi dan menghasilkan panas. Selain itu juga berpengaruh besar terhadap pengeresan semen, terutama sebelum mencapai umur 14 hari. Sebaliknya $\mathrm{C}_{2} \mathrm{~S}$ bereaksi dengan air lebih lambat sehingga berpengaruh terhadap pengerasan semen setelah berumur lebih dari 7 hari. Unsur $\mathrm{C}_{2} \mathrm{~S}$ ini juga membuat semen tahan terhadap serangan kimia dan juga mengurangi besar susutan pengeringan. Unsur $\mathrm{C}_{3} \mathrm{~A}$ berhidrasi secara exothermic dan bereaksi sangat cepat memberikan kekuatan sesudah 24 jam. Semen yang mengandung unsur ini lebih dari $10 \%$ akan kurang tahan terhadap serangan asam sulfat. Oleh karena itu, semen tahan 
sulfat tidak boleh mengandung $\mathrm{C}_{3} \mathrm{~A}$ terlalu banyak (maksimum 5\%). Semen yang terkena asam sulfat di dalam air atau tanah disebabkan karena keluarnya $\mathrm{C}_{3} \mathrm{~A}$ yang bereaksi dengan sulfat dan mengembang sehingga terjadi retak-retak pada betonnya. Perubahan komposisi kimia semen yang dilakukan dengan cara mengubah presentase empat komponen utama sehingga dapat menghasilkan beberapa tipe semen yang sesuai dengan tujuan pemakaiannya.

\section{Air}

Dalam pembuatan beton, air menjadi sangat penting karena air dapat bereaksi dengan semen yang akan menjadi pasta pengikat agregat. Air juga berpengaruh terhadap kuat tekan beton karena kelebihan air akan mengakibatkan beton menjadi bleeding, yaitu air bersama-sama semen akan naik keatas permukaan beton segar yang baru saja dituang. Hal ini akan menyebabkan kurangnya lekat antara lapisan-lapisan beton dan membuat menjadi lemah.

Air pada campuran beton akan berpengaruh terhadap:

a) Sifat workability adukan beton.

b) Besar kecilnya nilai susut beton.

c) Kelangsungan reaksi dengan semen Portland sehingga dihasilkan dan kekuatan selang beberapa waktu.

d) Perawatan keras adukan beton guna menjamin pengerasan yang baik.

Penggunaan air untuk beton sebaiknya air memenuhi persyaratan sebagai berikut:

a) Tidak mengandung lumpur atau benda melayang lainnya lebih dari 2 gram/liter.

b) Tidak mengandung garam-garam yang merusak beton (asam dan zat organik) lebih dari 15 gram/liter.

c) Tidak mengandung Klorida $(\mathrm{Cl})$ lebih dari 5 gram/liter.

d) Tidak mengandung senyawa sulfat lebih dari 1 gram/liter.

\section{Agregat}

Agregat adalah sekumpulan butir-butir batu pecah, kerikil, pasir atau mineral lainnya baik berupa hasil alam maupun buatan (SNI No: 17371989-F). Agregat adalah material granular, misalnya pasir, kerikil, batu pecah yang dipakai bersama-sama dengan suatu media pengikat untuk membentuk suatu beton semen hidraulik atau adukan.

Agregat berfungsi sebagai bahan pengisi dalam campuran mortar atau beton. Agregat ini kira-kira menempati sebanyak $70 \%$ dari volume mortar atau beton. Walaupun hanya sebagai bahan pengisi, akan tetapi agregat sangat berpengaruh terhadap sifat-sifat betonnya, sehingga pemilihan agregat merupakan suatu bagian penting dalam pembuatan beton.
Sifat yang paling penting dari suatu agregat (batu-batuan, kerikil, pasir dan lain-lain) ialah kekuatan hancur dan ketahanan terhadap benturan, yang dapat mempengaruhi ikatannya dengan pasta semen, porositas dan karakteristik penyerapan air yang mempengaruhi daya tahan terhadap proses pembekuan waktu musim dingin dan agresi kimia, serta ketahanan terhadap penyusutan.

Untuk menghasilkan beton dengan kekompakan yang baik, diperlukan gradasi agregat yang baik. Gradasi agregat adalah distribusi ukuran kekerasan butiran agregat. Gradasi diambil dari hasil pengayakan. Cara membedakan jenis agregat yang paling banyak dilakukan adalah dengan berdasarkan pada ukuran butiran-butirannya yang diuji melalui analisa saringan. Agregat yang mempunyai butiran-butiran yang besar disebut agregat kasar yang ukurannya lebih besar dari 4,75 $\mathrm{mm}$ atau tertahan pada saringan no. 4 yang berupa batu pecah (split) dan kerikil. Sedangkan butiran agregat yang kecil disebut agregat halus yang memiliki ukuran lebih kecil dari 4,75 $\mathrm{mm}$ atau lolos saringan no. 4 yang berupa pasir dan material halus lolos saringan lainnya.

Pasir yang digunakan dalam adukan beton harus memenuhi syarat sebagai berikut:

a) Butir-butirnya tajam, kuat dan bersudut.

b) Tidak mengandung tanah atau kotoran lain. Jumlah kandungan kotoran ini (lewat ayakan $0,15 \mathrm{~mm}$ ) harus tidak lebih dari $5 \%$ untuk pasir dan untuk kerikil maksimum $1 \%$.

c) Tidak berisi garam yang menghisap air dan udara.

d) Tidak mengandung zat-zat yang bereaksi dengan kapur atau semen. Kandungan zat organik dapat mengurangi mutu beton. Bila direndam dalam larutan $3 \% \mathrm{NaOH}$, cairan diatas endapan tidak boleh lebih gelapdari warna pembanding.

e) Memiliki variasu besar butir (gradasi) yang baik sehingga rongganya sedikit (untuk pasir modulus halus antara 1,5 - 3,8). Pasir yang seperti ini hanya memerlukan bahan ikat sedikit saja.

f) Bersifat kekal, tidak hancur atau berubah karena cuaca.

Agregat halus adalah pasir alam sebagai disintegrasi alami dari batuan atau pasir yang dihasilkan oleh industri pemecah batu dan mempunyai ukuran terbesar 4,8 $\mathrm{mm}$.

Agregat halus dapat digolongkan menjadi 5 (lima) macam yaitu:

a) Pasir Sungai

Pasir ini biasanya dengan kandungan lumpur yang lebih tinggi. Bentuk butirannya membulat.

b) Pasir Gunung

Jenis pasir ini biasanya berupa hasil letusan gunung berapi, mempunyai bentuk butiran 
yang menyudut dan biasanya mempunyai kadar lumpur yang lebih rendah.

c) Pasir Laut

Bila akan memakai pasir laut, perlu dicuci dahulu dan untuk pekerjaan-pekerjaan tertentu perlu diadakan penelitian.

d) Pasir dari Batu Pecah

Pasir ini biasanya diperoleh dari pemecahan bongkahan batu saat membuat batu pecah alami (natural crushed stone). Bentuk butirannya pipih dan lebih tajam sehingga mengurangi workability dan menghasilkan beton yang lebih berat.

e) Pasir Kwarsa

Pasir kwarsa biasanya diperoleh dari suatu penambangan di darat dan kandungan terbesarnya adalah silika. Beton dari pasir kwarsa akan memberikan bleeding yang berlebihan dan harus diperiksa kemungkinan terjadinya AAR (Alkali Aggregate Reaction).

Agregat kasar berupa pecahan batu, pecahan kerikil atau kerikil alami dengan ukuran butiran minimal $15 \mathrm{~mm}$ dan ukuran butiran maksimal 40 $\mathrm{mm}$. Ukuran maksimal dari beton bertulang diatur berdasarkan kebutuhan agregat tersebut harus dengan mudah dapat mengisi cetakan dan lolos dari celah-celah yang terdapat diantara batang-batang baja tulangan. Berdasarkan berat jenisnya, agregat kasar dibedakan menjadi 3 (tiga) golongan ${ }^{[9]}$ yaitu:

a) Agregat Normal

Agregat normal adalah agregat yang berat jenisnya antara 2,5-2,7 gram $/ \mathrm{cm}^{3}$. Agregat ini biasanya berasal dari agregat basalt, granit, kwarsa dan sebagainya. Beton yang dihasilkan mempunyai berat jenis sekitar 2,3 gram $/ \mathrm{cm}^{3}$.

b) Agregat Berat

Agregat berat adalah agregat yang mempunyai berat jenis lebih dari $2,8 \mathrm{gram} / \mathrm{cm}^{3}$, misalnya magnetic $\left(\mathrm{FeO}_{4}\right)$ atau serbuk besi. Beton yang dihasilkan mempunyai berat jenis tinggi sampai 5 gram $/ \mathrm{cm} 3$. Penggunaannya sebagai pelindung dari radiasi.

c) Agregat Ringan

Agregat ringan adalah agregat yang mempunyai berat jenis kurang dari 2,3 gram/cm3, yang biasanya dibuat untuk beton non structural atau dinding beton. Kebaikannya adalah berat sendiri yang rendah sehingga structural ringan dan pondasinya lebih ringan.

Dalam pelaksanan pekerjaan beton, besar butir agregat selalu dibatasi oleh ketentuan maksimal persyaratan agregat, ketentuan itu antara lain :

- Ukuran maksimum butir agregat tidak boleh lebih dari 3/4 kali jarak bersih antara baja tulangan atau antar tulangan dan cetakan.

- Ukuran maksimum butiran agregat tidak boleh lebih besar dari 1/3 kali tebal plat.

Tabel 1. Gradasi Agregat Kasar

\begin{tabular}{|c|c|c|}
\hline \multirow{2}{*}{$\begin{array}{c}\text { Lubang ayakan } \\
(\mathrm{mm})\end{array}$} & \multicolumn{2}{|c|}{$\begin{array}{c}\text { Persen bahan butiran yang lewat } \\
\text { ayakan }\end{array}$} \\
\cline { 2 - 3 } & \multicolumn{2}{|c|}{ Besar butiran maksimum } \\
\cline { 2 - 3 } & $40 \mathrm{~mm}$ & $20 \mathrm{~mm}$ \\
\hline 40 & $95-100$ & 100 \\
\hline 20 & $30-70$ & $95-100$ \\
\hline 10 & $10-35$ & $0-10$ \\
\hline 4.8 & $0-5$ & \\
\hline
\end{tabular}

(Sumber: Tri Mulyono, 2005)

- Ukuran maksimum butir agregat tidak boleh lebih besar dari 1/5 kali jarak terkecil antara bidang samping cetakan.

Agregat yang dapat dipakai harus memenuhi syarat-syarat :

1. Kerikil harus merupakan butir yang keras dan tidak berpori. Kerikil tidak boleh hancur adanya pengaruh cuaca. Sifat keras diperlukan agar diperoleh beton yang keras juga. Sifat tidak berpori untuk menghasilkan beton yang tidak mudah tembus air.

2. Kerikil harus bersih dari unsur organik.

3. Kerikil tidak boleh mengandung lumpur lebih dari $10 \%$ berat kering,lumpur yang dimaksud adalah agregat yang melalui ayakan diameter $0,063 \mathrm{~mm}$, bila lumpur melebihi $1 \&$ berat kering maka kerikil harus dicuci terlebih dahulu.

4. Kerikil mempunyai bentuk yang tajam. Dengan bentuk yang tajam maka timbul gesekan yang lebih besar pula yang menyebabkan ikatan yang lebih baik, selain itu dengan bentuk yang tajam akan membuat pasta semen mengikat agregat dengan baik.

Besar ukuran maksimum agregat mempengaruhi kuat tekan betonnya. Pada pemakaian ukuran butir agregat maksimum lebih besar memerlukan jumlah pasta semen lebih sedikit untuk mengisi rongga-rongga butirannya, bearti sedikit pula pori-pori betonnya (karena pori-pori beton sebagian besar berada dalam pasta, tidak dalam agregat) sehingga kuat tekannya lebih tinggi. Namun sebaliknya, karena butir-butir agregatnya besar maka luas permukaannya menjadi lebih sempit sehingga lekatan antara permukaan agregat dan pastanya kurang kuat. Indeks yang dipakai untuk ukuran kehalusan dan kekerasan butir agregat ditetapkan dengan modulus halus butir. Pada umumnya pasir mempunya modulus halus 1,5 sampai 3,8 dan kerikil antara 5 sampai 8 . Modulus halus butir campuran dihitung dengan rumus:

$$
w=\frac{k-c}{c-p} \times 100 \%
$$

Keterangan :

w : Persentase berat pasir terhadap berat kerikil

$\mathrm{k}$ : Modulus halus butir kerikil 
$\mathrm{p}$ : Modulus halus butir pasir

c : Modulus halus butir campuran

\section{Rencana Campuran Beton}

Tujuan dari perencanaan campuran beton adalah untuk menentukan proporsi semen, agregat halus dan agregat kasar serta air yang memenuhi syarat sebagai berikut:

1. Kekuatan desak: kuat desak yang dicapai pada usia 28 hari (atau usia yang ditentukan) harus memenuhi persyaratan yang diberikan oleh perencana kontruksinya.

2. Workabilitas: workabilitas sering diartikan sebagai tingkat kemudahan pengerjaan campuran beton untuk diaduk, dituang, diangkut, dan dipadatkan. Untuk memenuhi workabilitas yang cukup guna pengangkutan, pencetakan dan pemadatan beton sepenuhnya dengan peratalan yang tersedia. Pemilihan workabilitas yang paling sesuai biasanya merupakan tanggung jawab pemborong sepenuhnya dan hal ini penting, terutama bila beton dipompa atau digetarkan.

3. Durabilitas: durabilitas atau sifat awet berhubungan dengan kekuatan desak; semakin besar kekuatan, maka semakin awet betonnya. Meskipun demikian, sering terjadi kekuatan yang dipersyaratkan dapat tercapai dengan campuran yang besar faktor air/semennya daripada yang dapat memberikan durabilitas yang cukup terhadap lingkungan yang dialami beton. Dalam hal ini, faklor air/semen yang sebenarnya dan kepadatan beton merupakan faktor yang menentukan, dan kekuatannya mungkin akan lebih besar daripada yang dipersyaratkan dengan ketat untuk tujuan strukturil.

Pada penelitian ini, rancangan pembuatan campuran beton dibuat berdasarkan pada SNi-092834-2000 mengenai Tata Cara Pembuatan Rencana Campuran Beton Normal dimana tata cara ini meliputi persyaratan umum dan persyaratan teknis perencanaan campuran beton untuk digunakan sebagai salah satu acuan bagi para perencana dan pelaksana dalam merencanakan proporsi campuran beton tanpa menggunakan bahan tambah untuk menghasilkan mutu beton sesuai dengan rencana.

\section{Slump}

Slump adalah salah satu ukuran kekentalan adukan beton, dinyatakan dalam satuan $\mathrm{mm}$ ditentukan dengan alat kerucut abram sesuai dengan ketentuan SNI 1972-2008 mengenai Cara Uji Slump. Slump merupakan pedoman yang digunakan untuk mengetahui tingkat kecelakaan sualu adukan beton, semakin tinggi tingkat kekenyalan maka semakin mudah pengerjaannya (nilai workability tinggi). Pengujian ini dilakukan terhadap beton segar yang mewakili campuran beton. Hasil pengujian ini digunakan dalam pekerjaan:

1. Perencanaan campuran beton.

2. Pengendalian mutu beton pada pelaksanaan pembetonan.

Pengukuran slump harus segera dilakukan dengan cara mengukur tegak lurus antara tepi atas cetakan dengan tinggi rata-rata benda uji. Untuk mendapatkan hasil yang lebih teliti, dilakukan dua kali pemeriksaan dengan adukan yang sama dan dilaporkan hasil rala-rata.

\section{Kuat Tekan Beton}

Kuat tekan beton adalah perbandingan antara tingkatan beban yang diberikan dengan luas penampang. Kuat tekan beton biasanya berhubungan dengan sifat-sifat lain, maksudnya apabila kuat tekan beton tinggi, sifat-sifat lainnya juga baik. Kekuatan tekan beton dapat dicapai sampai $1000 \mathrm{~kg} / \mathrm{cm}^{2}$ atau lebih, tergantung pada jenis campuran, sifat-sifat agregat, serta kualitas perawatan.

Kekuatan tekan beton yang paling umum digunakan adalah sekitar $2200-500 \mathrm{~kg} / \mathrm{cm}^{2}$. Nilai kuat tekan beton didapatkan melalui tata cara pengujian standar, menggunakan mesin uji dengan cara memberikan beban ttekan bertingkat dengan kecepatan peningkatan beban tertentu dengan benda uji berupa kubus 150 x 150 mm. Selanjutnya, benda uji ditekan dengan mesin tekan sampai pecah. Beban tekan maksimum sampai benda uji pecah dibagi dengan luas penampang benda uji merupakan nilai kuat tekan beton yang dinyatakan dalam Mpa atau $\mathrm{kg} / \mathrm{cm}^{2}$ Tata cara pengujian yang umum dipakai adalah ASTMC39 atau menurut yang disyaratkan Peraturan Beton Indonesia (PBI) tahun 1989.

Kuat tekan sangat dipengaruhi oleh beberapa factor, antara lain:

1. Pengaruh mutu semen Portland

2. Pengaruh dari perbandingan adukan beton

3. Pengaruh air untuk membuat adukan

4. Pengaruh umur beton

5. Pengaruh waktu pencampuran

6. Pengaruh perawatan

7. Pengaruh bahan campuran tambahan

Rumus yang digunakan untuk perhitungan kuat tekan beton adalah;

$$
f^{\prime} c=\frac{P}{A}
$$

Keterangan :

$\mathrm{f}^{\prime} \mathrm{c}=$ Kuat tekan beton $(\mathrm{Mpa})$

$\mathrm{P} \quad=$ Beban maksimum $(\mathrm{kN})$

$\mathrm{A} \quad=$ Luas penampang benda uji $\left(\mathrm{cm}^{2}\right)$

\section{Mix Design}

Dalam perancangan beton diperlukan adanya formula umuk menghitung komposisi yang akan digunakan dalam pencampuran beton, formula ini disebut mix design atau job mix formula. Dengan 
adanya job mix formula maka diharapkan kuat karakteristik beton yang dikerjakan sesuai dengan yang direncanakan. Pembuatan job mix design ini berdasarkan tata cara yang ada pada SNI-09-28342000 .

\section{Metodologi Penelitian}

\section{Lokasi dan Tempat Penelitian}

Jenis penelitian ini merupakan penelitian laboratorium, harus mengetahui pengaruh pengaruh besar butiran agregat kasar pada sampel beton ini terhadap kuat tekan beton normal. Bahan bahan yang akan digunakan dan teknis pelaksanaan dalam penelitian mengacu pada Tata Cara Pembuatan Rancangan Beton Normal berdasarkan SNI 03-2834-2000. Metode yang digunakan pada penelitian ini merupakan penelitian laboratorium dengan pengujian benda uji yang dilakukan di laboratorium Pengujian Bahan Jurusan Teknik Sipil Politeknik Negeri Sriwijaya.

\subsection{Teknik Pengumpulan Data}

Teknik pengumpulan data merupakan langkah yang paling penting dalam penelitian, karena tujuan utama dari penelitian adalah mendapatkan data (Sugiyono 2008:62). Karena berdasarkan sifatnya merupakan penelitian kuantitatif, maka data yang diperoleh pada penelitian ini berdasarkan dua sumber, yakni data primer dan data sekunder. Selain itu peneliti juga melakukan studi literatur yang bersumber dari buku - buku sebagai acuan terkait dengan penelitian yang peneliti lakukan

\section{Data Primer}

Data primer merupakan data yang diperoleh dari hasil pengujian fisik material di laboratorium, yang terdiri dari pengujian terhadap agregat kasar, pengujian agregat halus dan pengujian semen pengujian ini dilakukan untuk mengetahui apakah material yang digunakan memenuhi sfesifikasi yang sesuai dengan Standar Nasional Indonesia.

\section{Data Sekunder}

Data Sekunder yang digunakan adalah jurnal jurnal penelitian terdahulu yang relevan dengan pengujian pengujian yang dilakukan.

Adapun jurnal - jurnal terkait yang dijadikan sebagai referensi adalah sebagai berikut:

a. Perbandingan Mutu Beton Hasil UPVT Metode Indirect terhadap Mutu Beton Hasil Hammer test dan Core Drill oleh Faisal Ridho dan Heri Khoeri dalam penelitian yang dilakukan di Jurusan Teknik Sipil Universitas Muhammadiyah Jakarta tahun 2015.

b. Pengaruh Kadar Air Agregat terhadap Kuat Tekan Beton oleh Arusmalem Ginting, Wawan Gunawan dan Ismirrozi dalam penelitian yang dilakukan di Fakultas Teknik
Jurusan Teknik Sipil Universitas Janabrada, Yogyakarta tahun 2011.

\section{Studi Literatur}

Studi Literatur adalah teknik yang dilakukan untuk menghimpun data - data terkait mengenai penelitian yang dilakukan yang didapat melalui studi pustaka. Studi Literatur digunakan untuk mendapatkan gambaran dan acuan yang jelas terhadap penelitian dan penyusunan laporan akhir berdasarkan buku - buku maupun sumber tertulis lain dan relevan dengan penelitian yang dilakukan.

\section{Tahapan Penelitian}

Pelaksanaan penelitian diawali dengan penyediaan material akan digunakan, selanjutnya dilakukan pengujian terhadap material yang telah tersedia apakah telah sesuai dengan Standar Nasional Indonesia kemudian dilakukan pengolahan data untuk mengetahui apakah material yang telah diuji tersebut dapat digunakan sebagai material penyusun beton. Setelah itu dilakukan perhitungan mix design beton dan dilanjutkan dengan pembuatan benda uji beton, yang nantinya akan dilakukan uji kuat tekan dan berdasarkan nilai kuat tekan beton tersebut didapat data yang nantinya akan dianalisa dan ditarik kesimpulan berdasarkan penelitian yang telah dilakukan.

\section{Persiapan Material}

Langkah awal dalam pelaksanaan penelitian adalah penyiapan material yang digunakan, dimulai dari proses pengangkutan, penyimpanan material dan pengujian terhadap material. Material material yang digunakan pada penelitian ini adalah sebagai berikut:

\section{Semen}

Semen yang digunakan adalah Semen Portland type I dengan merk dagang Semen Baturaja.

2. Agregat Kasar

Agregat Kasar yang digunakan dalam penelitian adalah batu pecah yang berasal dari Lahat.

3. Agregat Halus

Agregat halus yang digunakan dalam penelitian berasal dari Tanjung Raja.

4. Air

Air yang digunakan dalam penelitian berasal dari Laboratorium Jurusan Teknik Sipil Politeknik Negeri Sriwijaya.

\section{Analisis dan Pembahasan}

\section{Komposisi Material Campuran Beton}

Berdasarkan perhitungan mix design beton yang direncanakan, didapat jumlah material yang dibutuhkan untuk tiap $\mathrm{m}^{3}$ benda uji dengan jumlah sebagai berikut:

1. Benda uji dengan ukuran besar butir agregat kasar $1 / 2(20 \mathrm{~mm})$ 
- Semen Portland : $: 391,30 \mathrm{Kg}$

- Agregat Halus : $: 686,154 \mathrm{Kg}$

- Agregat Kasar 1/2 :947,546 Kg

- Air :225Kg/It

2. Benda uji dengan ukuran besar butir agregat kasar 2/3 (40 mm)

- Semen Portland :356,52 Kg

- Agregat Halus : $: 654,8 \mathrm{Kg}$

- Agregat Kasar $\quad: 1114,93 \mathrm{Kg}$

- Air :205 Kg/It

3. Benda uji dengan ukuran besar butir agregat kasar 1/2 -2/3 (20 mm)

- Semen Portland :356,52 Kg

- Agregat Halus $: 815,19 \mathrm{Kg}$

- Agregat kasar $\quad: 1389,24 \mathrm{Kg}$

- Air :205 Kg

\section{Analisa Perhitungan Pengujian Beton}

\section{Pengujian Slump Campuran beton}

Berikut ini merupakan hasil yang didapat dari pengujian slump pada masig-masing campuran beton yang dipakai.

Tabel 2. Hasil Pengujian Slump pada Campuran Beton Menggunakan Agregat Kasar ukuran 1/2

\begin{tabular}{|c|c|c|}
\hline No & Nilai Slump (cm) & Rata - rata Slump Beton $(\mathrm{cm})$ \\
\hline 1. & 10 & \multirow{3}{*}{8.33} \\
\hline 2. & 8 & \\
\hline 3. & 7 & \\
\hline
\end{tabular}

Tabel 3. Hasil Pengujian Slump pada Campuran Beton Menggunakan Agregat Kasar ukuran 2/3.

\begin{tabular}{|c|c|c|}
\hline No & Nilai Slump $(\mathrm{cm})$ & $\begin{array}{c}\text { Rata - rata Slump Beton } \\
(\mathrm{cm})\end{array}$ \\
\hline 1. & 12 & \\
\hline 2. & 10 & 10.16 \\
\hline 3. & 8.5 & \\
\hline
\end{tabular}

(Sumber : Hasil Pengujian di Laboratorium Teknik Sipil Pengujian Material, 2017)

Tabel 4. Hasil Pengujian Slump Pada Campuran Beton Menggunakan Agregat Kasar Ukuran 1/2 dan 2/3.

\begin{tabular}{|c|c|c|}
\hline No & Nilai Slump (cm) & Rata - rata Slump Beton $(\mathrm{cm})$ \\
\hline 1. & 9 & \multirow{3}{*}{7.66} \\
\hline 2. & 8 & \\
\hline 3. & 6 & \\
\hline
\end{tabular}

Pengujian Material, 2017)

Berdasarkan data pengujian slump beton diatas didapat nilai slump rata - rata untuk campuran beton menggunakan agregat ukuran $1 / 2$ yaitu $8.33 \mathrm{~cm}$, untuk campuran beton menggunakan agregat ukuran $2 / 3$ yaitu 10.16 , dan untuk agregat campuran beton yang menggunakan agregat ukuran $1 / 2$ dan $2 / 3$ yaitu 7.66 , hasil slump tersebut telah memenuhi persyaratan ukuran slump yang telah direncanakan pada job mix sebelumnya.

\section{Hasil Perhitungan Mutu Beton}

Berdasarkan Perhitungan mutu beton untuk tiap - tiap benda uji pada usia 28 hari dengan bentuk benda uji berupa kubus berukuran $15 \times 15 \times 15$ didapatkan nilai seperti pada lampiran dengan nilai rata - rata mutu beton sebagai berikut:

1. Benda uji dengan ukuran besar butir agregat kasar $1 / 2(20 \mathrm{~mm})$

Kubus ukuran $15 \times 15 \times 15 \mathrm{~cm} \quad: 174.6 \mathrm{Kg} / \mathrm{cm}^{2}$.

2. Benda uji dengan ukuran besar butir agregat kasar 2/3 (40 mm)

Kubus ukuran $15 \times 15 \times 15 \mathrm{~cm}: 247.76 \mathrm{Kg} / \mathrm{cm}^{2}$.

3. Benda uji dengan ukuran besar butir agregat kasar $1 / 2$ dan 2/3 (20 mm)

Kubus ukuran $15 \times 15 \times 15 \mathrm{~cm}: 138.53 \mathrm{Kg} / \mathrm{cm}^{2}$.

Berdasarkan hasil pengujian yang didapat menunjukkan adanya perbedaan kuat tekan yang signifikan $27 \%$ untuk butir agregat kasar maksimum 20 mm (agregat kasar 12), 37\% untuk butir agregat kasar maksimum $40 \mathrm{~mm}$ (agregat kasar 2/3) dan $38 \%$ untuk butir agregat maksimum $40 \mathrm{~mm}$ (agregat kasar campuran 1/2 dan 2/3).

Ini menandakan bahwa hasil pengujian core drill akan didapat mutu lebih rendah dari semestinya yang didapat sampel kubus. Dari hasil pengujian kuat tekan tersebut, dapat dibuat grafik hasil pengujian mutu beton sebagai berikut.

Grafik Kuat Tekan Sampe Kubus Terhadap Ukuran Agregat Kasar

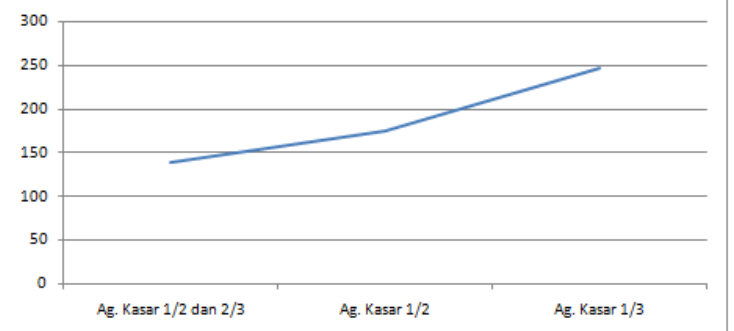

Gambar 1. Kuat Tekan Sampel Kubus terhadap Ukuran Agregat Kasar.

Kesimpulan akhir dari penelitian yaitu terdapat pengaruh yang sangat besar dengan berbagai jenis ukuran butir agregat kasar. Hal yang sama terdapat peningkatan mutu beton yang berbanding lurus dengan besaran butir agregat kasar yang digunakan seperti pada grafik.

\section{Kesimpulan}

1. Pemilihan material yang berkualitas baik perlu dilakukan agar beton yang hendak dibuat 
mampu mencapai nilai kuat tekan yang direncanakan.

2. Hasil pengujian kuat tekan beton dilakukan pada usia beton mencapai 28 hari agar mendapatkan hasil kuat tekan yang maksimal.

3. Besar butiran agregat kasar mempengaruhi nilai kuat tekan beton yang dicapai baik untuk beton berbentuk kubus maupun agregat kasar yang memiliki ukuran butir maksimum lebih besar memiliki nilai kuat tekan yang besar daripada agregat kasar yang memiliki ukuran lebih kecil.

4. Jumlah pemakaian semen untuk mutu yang sama dengan ukuran agregat yang berbeda membutuhkan jumlah semen yang berbeda pula, ada kecenderungan bahwa semakin kecil agregat yang dipakai maka kebutuhan semen yang diperlukan semakin banyak.

\section{Daftar Pustaka}

[1] L.J. Murdock, dkk. 1999. Bahan dan Praktek Beton (Edisi keempat). Jakarta: Erlangga
[2] Pramono Didiek dan Suryadi H.S. 2008. Bahan Konstruksi Beton. Depok: Gunadarma

[3] Sageling R, dkk. 1993. Pedoman Pengerjaan Beton. Jakarta: Erlangga

[4] Peraturan Beton Bertulang Indonesia. 1971. Direktorat Penyelidikan Masalah Bangunan Departemen Pekerjaan Umum dan Tenaga Listrik

[5] SNI 03-2834-2000 tentang Tata Cara Pembuatan Rencana Campuran Beton Normal

[6] SNI-2492-2002 tentang Metode Pengambilan dan Pengujian Beton Inti

[7] SNI-1974-2011 tentang Cara Uji Kuat Tekan Beton dengan Benda Uji Silinder

[8] Mark Fintel. Buku Pegangan untuk Teknik Beton

[9] Ir. Tri Mulyono, MT. 1987. Teknologi Beton. Jakarta: PT. Pradnya Paramita

[10] Drs. Daryanto. 2009. Pengetahuan Teknik Bangunan. Jakarta: Rineka Cipta 